\title{
Evidence supporting the use of a subjective staff evaluation to assess the benefit of rehabilitation in hemodialysis patients undergoing inpatient rehabilitation
}

\author{
Takahiro Shimoda ${ }^{1}$, Helen Alston ${ }^{2}$, Angelique Chai ${ }^{2}$ and Sarbjit V. Jassal ${ }^{2^{*}}$ (D)
}

\begin{abstract}
Background: We questioned whether the introduction of a subjective evaluation of patient-specific goals, could be used as a valid method to assess the effectiveness of inpatient rehabilitation.

Methods: In this prospective cohort study, all admissions to the UHN hemodialysis rehabilitation service between April 2013 and August 2016 were included. We introduced a system of subjective assessment, performed by the team at the time of admission and discharge. We evaluated Functional Independence Measure $\left(\mathrm{FIM}^{\oplus}\right) \mathrm{score}$ and KDQoL for objective measures of physical function and patient-reported quality of life.

Results: A total of 201 patients were included. The median FIM score at discharge correlated well with the subjective staff evaluation. FIM score changes for those with evaluations for Success, Partial success, and Not Successful were 28 [interquartile range (IQR) 20-34], 24 [IQR18-31], 16 [IQR 11-34] respectively. The median PCS at discharge for those deemed to have Success was 37.4 [IQR31.0, 44.7], and for those with Partial success \& Not Successful 28.8 [IQR 22.4, 39.2]. There was no correlation with MCS scores (55.2 [IQR 51.2, 60.2], 58.4 [IQR 50.1, 63.1] respectively).

Conclusions: These results suggest the subjective staff evaluation is a brief but valid assessment of patient outcome for dialysis patients undergoing inpatient rehabilitation.
\end{abstract}

Keywords: ADL, Hemodialysis patients, QOL, Rehabilitation, Staff subjective evaluation

\section{Background}

The goal of rehabilitation is to optimize an individual's functioning despite disease, injury or other health conditions. Specific activity goals are determined in the context of the individual's lifestyle and resources, as well as with regard to how they interact with their physical, attitudinal and social environment [1]. Thus when evaluating whether a period of rehabilitation has gone well, it is important to include the individual expectations for

\footnotetext{
* Correspondence: vanita.jassal@uhn.ca

${ }^{2}$ Division of Nephrology, University Health Network, Toronto, Canada Full list of author information is available at the end of the article
}

their own lifestyle together with their ability to complete functional tasks. To capture patient-specific goals into the evaluation of rehabilitation outcomes, we established a process where goals were identified and reassessed, subjectively, by the clinicians at both admission and discharge. This subjective-staff evaluation was applied to all admissions in a unit providing inpatient rehabilitation care to patients maintained chronically on hemodialysis (HD).

The objective of this study was to evaluate if the subjective staff evaluation was validated by objective measures of rehabilitation success (determined from 
the Functional Independence Measure $\left(\mathrm{FIM}^{\circ}\right)$ score [2]) and by changes in patient-reported quality of life scores (measured using the KDQoL [3]).

\section{Methods}

Data were obtained from an ongoing prospective cohort study of patients undergoing rehabilitation and hemodialysis (HD) at the Toronto Rehabilitation Institute, University Health Network, Toronto. All admissions to the hemodialysis rehabilitation service between April 2013 and August 2016 were included. Patient characteristics were determined from the prospectively-maintained clinical database and included age, sex, time on renal replacement therapy, cause of renal failure, reason for rehabilitation, comorbidity condition, hemoglobin, albumin, serum creatinine, and depressive symptoms. The study was approved by the University Health Network research ethics board. All patients received a thorough explanation of the study and only patients able and willing to provide written consent were included.

At the time of admission, realistic goals were set by the rehabilitation clinicians and the patient collectively, and documented in the chart (Appendix). At the time of discharge, each goal was evaluated, and compared to the patient's function at that time. The team collectively assessed the proportion of patient-specific rehabilitation goals that had been met into three groups: $<30 \%$ (subjective evaluation 'not successful'); 30-69\% (subjective evaluation 'partial success'); $\geq 70 \%$ (subjective evaluation 'success'). To ensure team consensus, a minimum of three different health care disciplines had to be involved in the discharge evaluation (occupational therapy/ physiotherapy/ recreational therapy/ rehabilitation nurse/ unit physicians).

The objective change in physical function, attributable to rehabilitation, was quantified using the change in FIM $^{\bullet}$ [2] score over the admission period. Admission and discharge FIM $^{\circ}$ scores are collected routinely in the minimal dataset for centers providing active inpatient rehabilitation in Ontario. The score is a validated measure of independence in core daily activity, and comprises 13 motor items and 5 cognitive items, with each item worth 7 points $(1$ - complete assistance, to 7 - complete independence). A maximal score of 126 is consistent with independence in all activities of daily living, while 18 is the lowest score possible.

A subset of patients also completed the KDQoL-36 [3] at both admission and discharge. The KDQoL-36 has 36 items that include all items within the ShortForm-12 (SF-12) generic quality of life scale, plus 24 disease-specific kidney-related items. KDQoL results are often further subdivided into physical component scores (PCS) and mental component scores (MCS).
Demographic and clinical data were reported using mean and standard deviation for parametric data or median and interquartile range (IQR) if non-parametric. Categorical variables were reported as a percentage. Differences were assessed using unpaired T-tests (for parametric variables), or Mann-Whitney $U$ test (non parametric). Categorical data were assessed using the chi-squared test. The association between subjective staff evaluation scores and the change in physical function measured by change in $\mathrm{FIM}^{\circ}$; and the change in QOL score was assessed using the Kruskal-Wallis test. All analyses were performed using the $\mathrm{R}$ statistical software (version 3.3.0; $\mathrm{R}$ Foundation for Statistical Computing, Vienna, Austria). In all analyses, $P<0.05$ was taken to indicate statistical significance.

\section{Results}

A total of 249 patients underwent rehabilitation and dialysis over the 35 month study period. Of these 11 had an incomplete FIM at baseline and 37 had an incomplete FIM at discharge (Fig. 1) resulting in a total of 201 participants with complete FIM results. Patients who had a complete follow up FIM $^{\circ}$ were mostly male $(57 \%, n=115)$, with a mean age of 71.5 years (interquartile range, 64.9-78.9) (Table 1). One hundred forty- three of the patients underwent rehabilitation for acute hospitalization, 59 were admitted for rehabilitation after an acute fall. The median length of stay was 41 days (IQR $31-47$ ). More than $80 \%$ of patients succeeded in $\geq 70 \%$ of the goals identified at admission ( $n=163,81.1 \%)$. Of the remaining patients $30(14.9 \%)$ and $8(4.0 \%)$, achieved $30-69 \%$ of goals or $<30 \%$ of goals respectively. The median $\mathrm{FIM}^{\circledR}$ score at the time of admission was $77(n=238$, IQR $68-89)$ and at discharge $110 \quad(n=201$, IQR 97-117)). Ninety-nine patients did not give consent to participation in the quality of life assessment. As only one patient with complete KDQOL data fell in the Not Successful group, data for those with Partial Success and Not Successful were condensed into one group for all analyses involving KDQOL data.

The subjective staff evaluation corresponded well with discharge FIM $^{\bullet}$ scores (Success: 111 [IQR 104118], Partial Success: 93 [IQR 82-109], Not Successful: 86 [71-102], Fig. 2; $P<0.001)$. At the time of discharge, patients with a subjective staff evaluation "success" had higher quality of life scores than those in the other groups although this was largely due to changes in physical component scores (median PCS scores of 37.4 [IQR 31.0-44.7] compared to 28.8 [IQR 22.4-39.2] for those in the combined Partial Success $\mathcal{E}$ Not Successful group). MCS scores at discharge were similar across groups 55.2 [IQR 51.2-60.2] and 58.4 [IQR 50.1-63.1] respectively. 


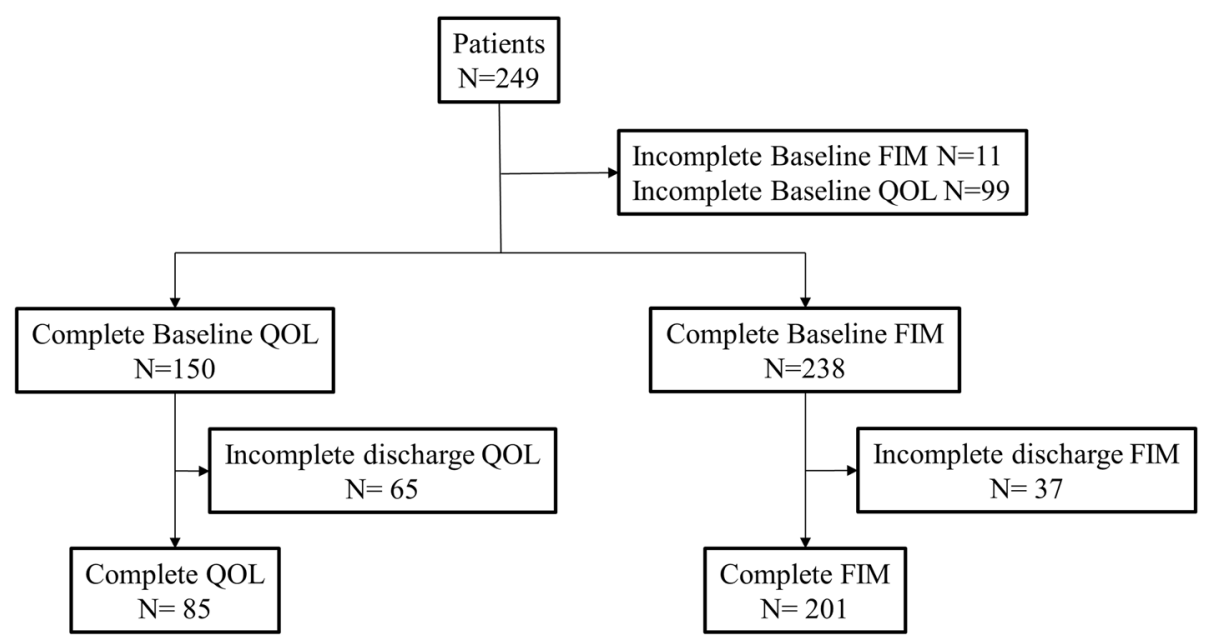

Fig. 1 Flow diagram showing Study recruitment

The subjective staff evaluation correlated only weakly with absolute change in $\mathrm{FIM}^{\ominus}$ scores (Success: 28 [IQR 20-34], Partial Success: 24 [IQR 18-31], Not Successful: 16 [IQR 11-34], Fig. 3) and in PCS scores (Success: 8 [IQR 0-14], Partial Success \& Not Successful: 1 [IQR -4 - 7]) and MCS scores (Success: 10 [IQR -2 - 17], Partial
Success \& Not Successful: 5 [IQR -3 - 12] (Fig. 4). However when defined using a threshold for improvement, more patients reported substantial improvements in quality of life (defined as $>5$ point change in PCS scores over time) in those with Success than the combined Partial Success \& Not Successful group (for PCS change

Table 1 Demographic and clinical details of study population

\begin{tabular}{|c|c|c|c|}
\hline & $\begin{array}{l}\text { Target Study population } \\
N=249\end{array}$ & $\begin{array}{l}\text { Complete FIM data } \\
N=201\end{array}$ & $\begin{array}{l}\text { Complete KDQoL data } \\
N=85\end{array}$ \\
\hline Age, year & $71.7[64.9-79.1]$ & $71.5[64.9-78.9]$ & $68.9[63.9-76.7]$ \\
\hline Female, \% & $102(41.0)$ & $86(42.8)$ & $36(42.4)$ \\
\hline \multicolumn{4}{|l|}{ Dialysis vintage, \% } \\
\hline$<3$ months & $78(31.3)$ & $68(33.8)$ & $30(35.3)$ \\
\hline 3 to12 months & $31(12.4)$ & $21(10.4)$ & $12(14.1)$ \\
\hline $12<$ months & $140(56.2)$ & $112(55.7)$ & $43(50.6)$ \\
\hline \multicolumn{4}{|l|}{ Cause of Renal Failure, \% } \\
\hline DM and HT/vascular & $126(50.6)$ & $106(52.7)$ & $38(44.7)$ \\
\hline GN & $31(12.4)$ & $25(12.4)$ & $14(16.5)$ \\
\hline Other & $81(32.5)$ & $59(29.4)$ & $25(29.4)$ \\
\hline Modified Charlson score, score & $6[3-8]$ & $6[4-8]$ & $5[3-7]^{a}$ \\
\hline Length of stay & $41[31-47]$ & $42[33-47]$ & $41[31-46]$ \\
\hline \multicolumn{4}{|l|}{ Medical Reason for Rehabilitation, \% } \\
\hline Acute hospitalization & $143(57.4)$ & $111(55.2)$ & $51(60.0)$ \\
\hline Fall & $59(23.7)$ & $51(25.4)$ & $18(21.2)$ \\
\hline Other & $47(18.9)$ & $39(19.4)$ & $16(18.8)$ \\
\hline Albumin, g/L & $31[28-34]$ & 31 [29-34] & 31 [28-34] \\
\hline Creatinine, mg/L & $478[350-602]$ & 491 [358-611] & 503 [370-611] \\
\hline Hemoglobin, g/L & 96 [87-105] & 96 [87-103] & 95 [87-102] \\
\hline
\end{tabular}

Values are shown as median [IQR] or $\mathrm{n}(\%)$

a: $p<0.05$ vs Target Study population 


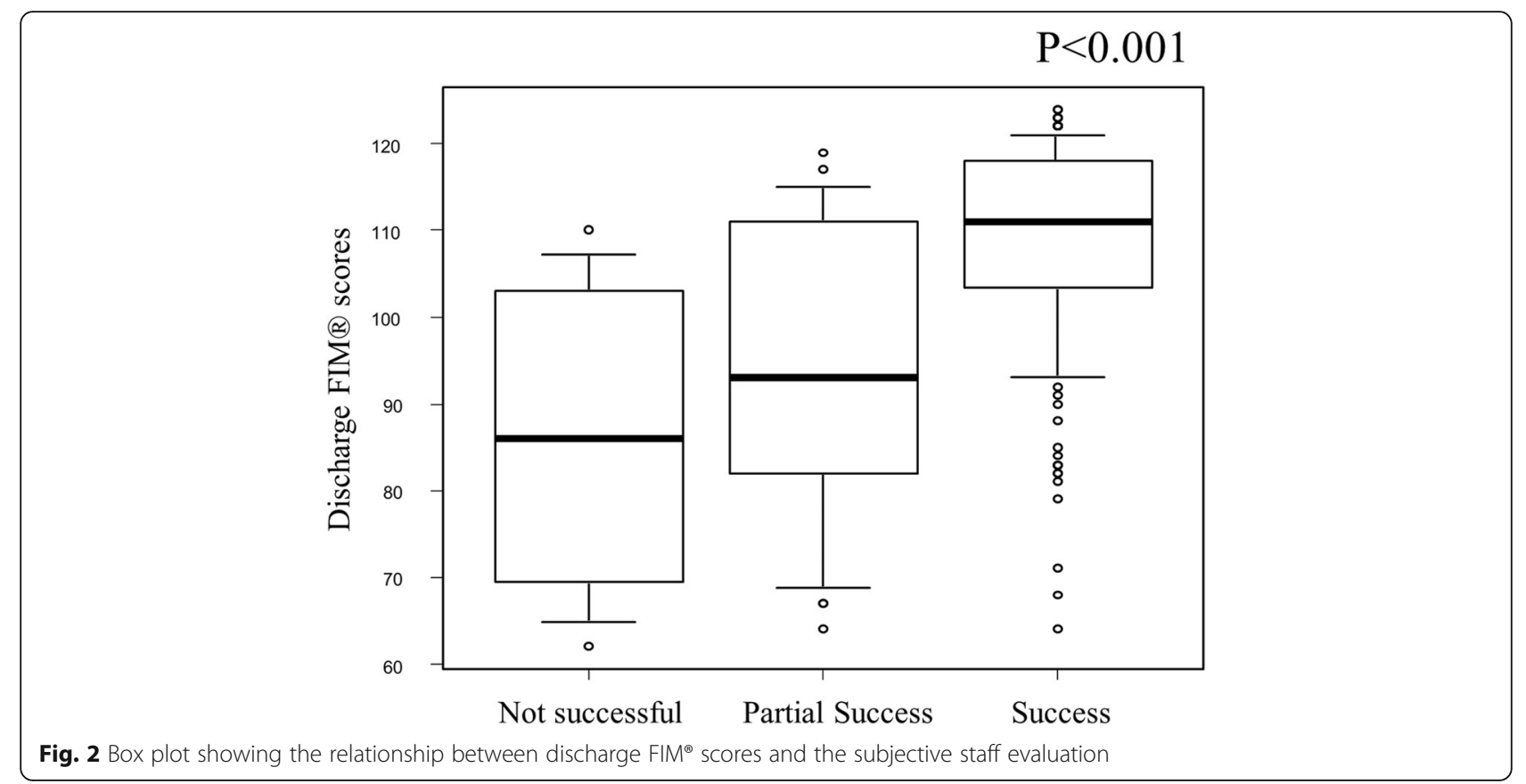

$n=44,60 \%$ vs. $\mathrm{n}=4,40 \%$ respectively). A similar trend was not seen with change in baseline MCS change ( $n=38,51 \%$ vs $n=6,60 \%$ respectively).

\section{Discussion}

The data presented in this study suggest that the routine use of a staff subjective evaluation is a valid quick assessment tool that corresponds with objective measures of physical function and patient-reported quality of life. The assessment is rapid and easily applied and has the added advantage of being specific to an individual's needs and goals. We therefore suggest it may be an appropriate method to assess the success of our rehabilitation program although acknowledge that

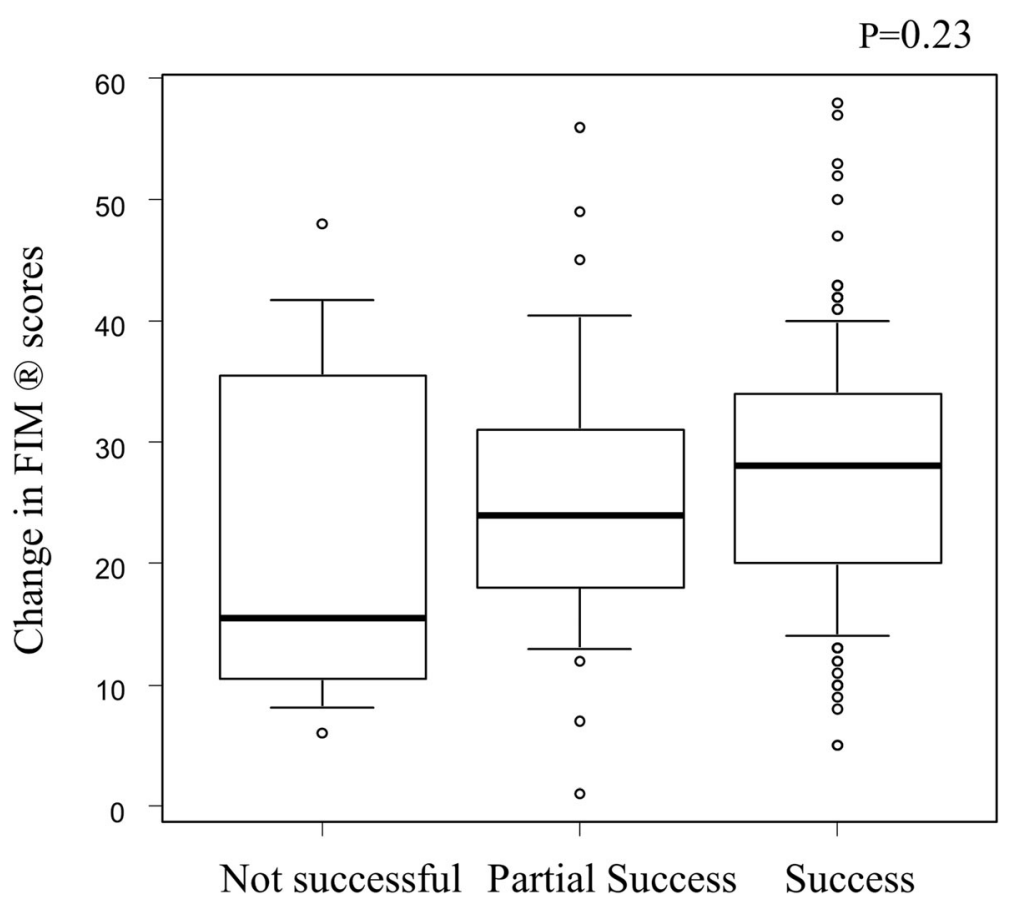

Fig. 3 Box plot showing the relationship between the change in FIM ${ }^{\bowtie}$ score and subjective staff evaluation 

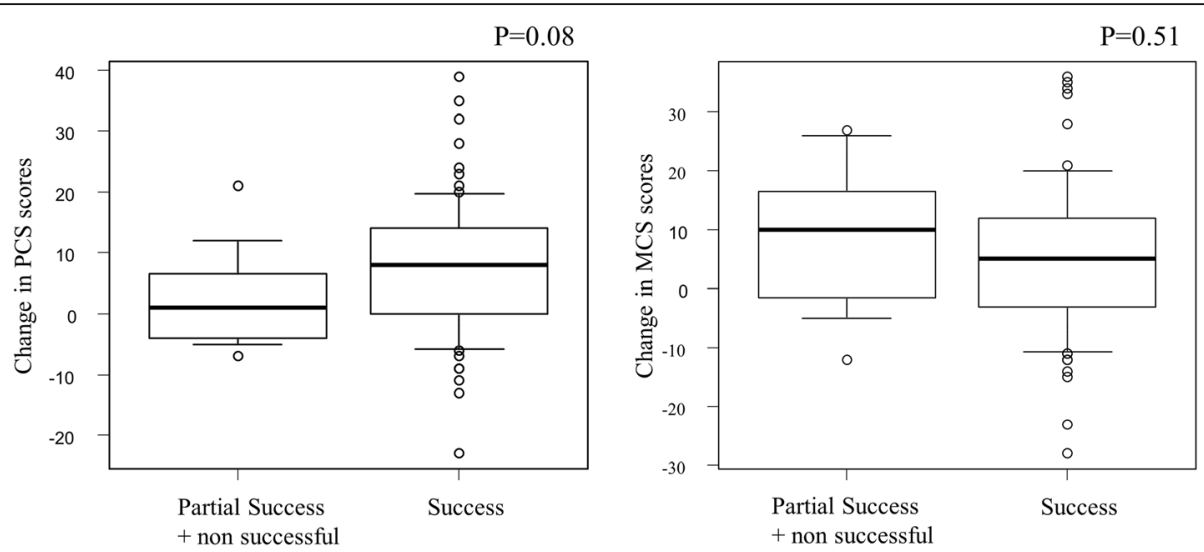

Fig. 4 Box plot showing the change in both the Physical Component Score (PCS) and Mental Component Scores (MCS) measured on the KDQOL-36 and subjective staff evaluation

further work is required to assess if it can be used to estimate prognosis and long term outcomes. Similar methods have been proposed in other areas of rehabilitation such as paediatric rehabilitation, neurorehabilitation and in those using prosthetics for example $[4,5]$. However in a geriatric dialysis population, the use of traditional goal attainment scaling methods may be more challenging due to the multiple dimensions of goals, and the challenge of concomitant medical instability.

We chose to study a small group of hemodialysis patients undergoing rehabilitation as part of a project to assess the value of subjective team evaluation. Although dialysis patients have a unique and often complex pattern of comorbidity, the nature of their impairment and disability is similar to the general rehabilitation population. Consistent with this expectation, recent studies show the magnitude of improvement with rehabilitation, in patients recently started onto dialysis, to be similar to that of nondialysis patients [6-8]. The study population has similar characteristics to other studies of dialysis patients suggesting low risk of selection bias and that our findings may be widely generalizable [9-21]. For example, Forrest et al., reported that the median change in FIM scores, in $40 \mathrm{HD}$ patients, with a mean age of 69 years, undergoing inpatient rehabilitation was similar to our population (a change from mean baseline scores of 80 to 104 by discharge) [11]. Our multidisciplinary team is highly experienced at obtaining detailed information about the patient's characteristics, physical function, social factors and environmental factors, and therefore at setting realistic rehab goals for each patient. As a result our findings may not be generalisable to units with fewer health professionals or a less experienced team. The high burden of depression, and its modest responsiveness to treatment is increasingly recognized in the dialysis literature. We were therefore not surprised to find little correlation with physical outcomes and MCS scores, however we also acknowledge that our findings may in part relate to the small study sample, and to the nature of the KDQoL assessment of mental health wellbeing.

The data are limited by several factors. We did not include a validation cohort or long-term follow up data. A total of 12 patients did not have FIM data at baseline or follow up for unclear reasons. Another 37 did not have discharge FIM scores, mostly because these patients became acutely unwell and were transferred emergently to another acute care institution. Thus it is possible that our results are biased towards the inclusion only of those doing well with rehabilitation. Similarly a substantial number of patients did not complete both admission and discharge quality of life questionnaires limiting generalizability. Our study is also of relatively small size, and may not be generalizable across units with smaller teams or fewer health disciplines.

\section{Conclusion}

We propose that the use of a simple staff subjective evaluation is a valid clinical tool that can be easily used to assess improvement in functional and physical aspects after rehabilitation. As little to no change was seen in the mental health scores on the KDQoL, it remains unclear whether the evaluation tool is able to capture changes in emotional wellbeing, were they to have occurred. Further studies are needed to determine whether this subjective evaluation can be extended to other patient subgroups. 


\section{Appendix}

Table $\mathbf{2}$ Examples of patient-rehabilitation Goals identified at admission

To be able to walk from sitting room to bathroom in current home setting with or without a cane $(42 \mathrm{~m})$.

To be able to safely transfer in and out of the backseat of Ambassador taxi cab to wheelchair post-dialysis with either no assistance or one person supervision

To safely manage erythropoietin administration in home setting

To be able to transfer between dialysis chair and wheelchair with 1person assist

To be able to walk $300 \mathrm{~m}$ with/without walker

To be able to safely manage outdoor step (home setting)

To climb 6 stairs (after installation of new indoor stair rail)

To maintain balance using two-feet stance for 4 min (to allow opening of condominium door lock)

To be able to toilet independently

To reduce fall risk in bathroom while performing daily grooming tasks

To feed independently using nondominant hand (train in use of modified dishes and cutlery)

To use non verbal communication skills eg picture charts

To be able to get to church twice per week

To control pain in L Knee

\section{Abbreviations}

FIM ${ }^{\bullet}$ : Functional Independence Measure; HD: Hemodialysis; IQR: Interquartile range; KDQoL: Kidney Disease Quality of Life score; MCS: Mental component score; QOL: Quality of life; PCS: Physical component score

\section{Acknowledgments}

The authors would like to thank the patients and hemodialysis nursing team without whom this study would not have been possible.

\section{Authors' contributions}

Conception or design, or analysis and interpretation of data, or both: TS, HA, AC, SVJ. Analysis, drafting and revision of the article: TS Critical appraisal and important intellectual content: TS, HA, AC, SVJ; Final approval and responsibility for the authenticity of the data, interpretation and content of the version to be published: SVJ. Each author contributed important intellectual content during manuscript drafting or revision. All authors have read and approved the manuscript.

\section{Funding}

None.

\section{Availability of data and materials}

The datasets used and/or analysed during the current study available from the corresponding author on reasonable request.

\section{Ethics approval and consent to participate}

The study was approved by the University Health Network research ethics board and was conducted in accordance with the standards set forth by the latest revision of the Declaration of Helsinki. All patients received a thorough explanation of the study and only those patients that provided written consent were included.

\section{Consent for publication}

This manuscript has been seen and approved by all authors.

\section{Competing interests}

The authors declare no conflict of interest with regard to this study.

\section{Author details}

'Department of Rehabilitation Sciences, Kitasato University Graduate School of Medical Sciences, Sagamihara, Japan. ${ }^{2}$ Division of Nephrology, University Health Network, Toronto, Canada.

Received: 8 March 2020 Accepted: 21 October 2020

Published online: 09 November 2020

\section{References}

1. Stucki G, Cieza A, Melvin J. The international classification of functioning, disability and health (ICF): a unifying model for the conceptual description of the rehabilitation strategy. J Rehabil Med. 2007;39(4):279-85. https://doi. org/10.2340/16501977-0041.

2. Granger C, Hamilton B, Keith R, Zielezny M, Sherwin F. Advances in functional assessment for medical rehabilitation. Topics Geriatric Rehabilitation. 1986;1(3):59-74.

3. Hays RD, Kallich JD, Mapes DL, Coons SJ, Carter WB. Development of the kidney disease quality of life (KDQOL) instrument. Qual Life Res. 1994;3(5): 329-38.

4. Turner-Stokes L. Goal attainment scaling (GAS) in rehabilitation: a practical guide. Clin Rehabil. 2009;23(4):362-70. https://doi.org/10.1177/ 0269215508101742

5. Krasny-Pacini A, Hiebel J, Pauly F, Godon S, Chevignard M. Goal attainment scaling in rehabilitation: a literature-based update. Annals Physical Rehabil Med. 2013;56(3):212-30. https://doi.org/10.1016/j.rehab. 2013.02.002.

6. Farragher J, Einbinder Y, Oliver MJ, Nachman J, Chow E, Jassal SV. Importance of early inpatient geriatric rehabilitation on outcomes in individuals on Dialysis. Arch Phys Med Rehabil. 2020;101(2):227-33. https://doi.org/10.1016/j.apmr.2019.08.472.

7. Matsuzawa R, Hoshi K, Yoneki K, Harada M, Watanabe T, Shimoda T, Yamamoto S, Matsunaga A. Exercise training in elderly people undergoing hemodialysis: A systematic review and meta-analysis. Kidney International Reports. 2017;2(6):1096-110. https://doi.org/10.1016/j.ekir. 2017.06.008.

8. Shimoda T, Matsuzawa R, Hoshi K, Yoneki K, Harada M, Watanabe T, Matsunaga A. Effects of supervised exercise on depressive symptoms in hemodialysis patients: a systematic review and meta-analysis of randomized controlled trials. Renal Replacement Therapy. 2017:3(1):56.

9. Endo M, Nakamura Y, Murakami T, Tsukahara H, Watanabe Y, Matsuoka Y, Ohsawa I, Gotoh H, Inagaki T, Oguchi E. Rehabilitation improves prognosis and activities of daily living in hemodialysis patients with low activities of daily living. Physical Therapy Res. 2017;20(1):9-15. https://doi.org/10.1298/ ptr.E9898.

10. Farragher J, Jassal SV. Rehabilitation of the geriatric dialysis patient. Semin Dial. 2012;25(6):649-56. https://doi.org/10.1111/sdi.12014.

11. Forrest $\mathrm{G}$, Nagao M, Iqbal A, Kakar R. Inpatient rehabilitation of patients requiring hemodialysis: improving efficiency of care. Arch Phys Med Rehabil. 2005;86(10):1949-52. https://doi.org/10.1016/j.apmr. 2005.04.006.

12. Frank CM, A.R. Rehabilitation of geriatric patients on hemodialysis: a case series. Geriatr Today, 2002:5:136-9.

13. Ifudu O, Mayers J, Matthew J, Tan CC, Cambridge A, Friedman EA. Dismal rehabilitation in geriatric inner-city hemodialysis patients. JAMA. 1994;271(1):29-33.

14. Ifudu O, Paul H, Mayers JD, Cohen LS, Brezsnyak WF, Herman Al, Avram MM Friedman EA. Pervasive failed rehabilitation in center-based maintenance hemodialysis patients. Am J Kidney Dis. 1994;23(3):394-400 doi: S0272638694000545 [pii].

15. Jassal SV, Chiu E, Li M. Geriatric hemodialysis rehabilitation care. Adv Chronic Kidney Dis. 2008;15(2):115-22. https://doi.org/10.1053/j.ackd. 2008.01.008.

16. Kutner NG, Brogan DJ. Assisted survival, aging, and rehabilitation needs: comparison of older dialysis patients and age-matched peers. Arch Phys Med Rehabil. 1992;73(4):309-15.

17. Kutner NG, Jassal SV. Quality of life and rehabilitation of elderly dialysis patients. Semin Dial. 2002;15(2):107-12.

18. Kutner NG, Zhang R, Huang Y, Herzog CA. Cardiac rehabilitation and survival of dialysis patients after coronary bypass. J Am Soc Nephrol. 2006;17(4): 1175-80. https://doi.org/10.1681/ASN.2005101027. 
19. Li M, Porter E, Lam R, Jassal SV. Quality improvement through the introduction of interdisciplinary geriatric hemodialysis rehabilitation care. Am J Kidney Dis. 2007;50(1):90-7. https://doi.org/10.1053/j.j.jkd. 2007.04.011.

20. Mercer TH, Crawford C, Gleeson NP, Naish PF. Low-volume exercise rehabilitation improves functional capacity and self-reported functional status of dialysis patients. Am J Phys Med Rehabil. 2002;81(3):162-7.

21. Pianta TF, Kutner NG. Improving physical functioning in the elderly dialysis patient: relevance of physical therapy. Anna J. 1999;26(1):11-4 quiz 15-16.

\section{Publisher's Note}

Springer Nature remains neutral with regard to jurisdictional claims in published maps and institutional affiliations.

Ready to submit your research? Choose BMC and benefit from:

- fast, convenient online submission

- thorough peer review by experienced researchers in your field

- rapid publication on acceptance

- support for research data, including large and complex data types

- gold Open Access which fosters wider collaboration and increased citations

- maximum visibility for your research: over $100 \mathrm{M}$ website views per year

At BMC, research is always in progress.

Learn more biomedcentral.com/submissions 